
\title{
25 Research Soure \\ The Effects of Educational Intervention on Operating Room Nurses' Application of Electrosurgical Units
}

\section{Armin Fereidouni}

Shiraz University of Medical Sciences

Mina Amiri

Shiraz University of Medical Sciences

Mostafa Bijani

Fasa University of Medical Sciences

Seyed Alireza Moayedi

Shiraz University of Medical Sciences

Camellia Torabizadeh ( $\nabla$ torabik@sums.ac.ir)

Shiraz University of Medical Sciences

\section{Research Article}

Keywords: Electrosurgical unit, Nurses, Nursing, Operating room, Electrocautery

Posted Date: February 12th, 2021

DOI: https://doi.org/10.21203/rs.3.rs-189645/v1

License: (c) (1) This work is licensed under a Creative Commons Attribution 4.0 International License. Read Full License 


\section{Abstract}

Background: An electrosurgical unit is one of the most essential pieces of equipment in operating rooms. Over $80 \%$ of operations today make use of electrosurgical units. Training operating room nurses in correct application of electrosurgical units and evaluation of their application play a key role in making optimal use of the units and extending their lifetime, reducing occupational hazards for surgical teams, and enhancing the safety of patients. The present study aims to investigate the effects of an educational intervention on operating room nurses' application of electrosurgical units.

Methods: The present study is a quasi-experimental work of research conducted in all the operating rooms of the hospitals located in Shiraz, Iran. Data were collected from 200 observations of 200 surgeries (100 before intervention and 100 after). The content of education was derived from a literature review and standard guidelines and was presented as a poster in the operating rooms. The data collection instruments consisted of a Demographic Information Questionnaire, a surgery checklist, and the checklist for operating room Nurses' application of electrosurgical units. Data were collected once before the intervention and then again one month after the intervention. The collected data were analyzed using the descriptive statistics of chi-square test and paired t-test at a significance level of 0.05 in SPSS v. 18.

Results: The average age of the participating nurses was $31.540 \pm 6.772$ years. The majority of the participants were female. The results showed a statistically significant difference between the means and standard deviations of the nurses' application of electrosurgical units scores before $(18.330 \pm 2.666)$ and after $(20.820 \pm 3.400)$ intervention.

Conclusion: Introducing operating room nurses to the standard guidelines for application of electrosurgical units can improve the quality of services provided by the nurses, increase the safety of patients, and reduce occupational hazards. Thus, to improve operating room nurses' professional performance in application of electrosurgical units, medical managers and policy-makers should attach more importance to on-the-job training programs.

\section{Background}

Today, electrosurgical units are an indispensable part of most operations [1]. They have been in use for about 90 years and have a direct impact on clinical results [1-4]. By allowing for hemostasis during surgery, electrosurgical units give the surgical team better visual access to the area under surgery [2], reduce the need for blood transfusion, curtail the length of anesthesia and surgery, and prevent local hematomas after surgery [2-6].

The consequences of incorrect use of electrosurgical units for patients and the surgical team include: skin burns, inhalation of electrosurgical smoke, fire occurrence in the operating room, and disruption in the functioning of cardiac pacemakers [7]. Skin burns from return electrodes are always caused by negligence for which surgeons can be held liable [8]. According to the Occupational Safety and Health 
Administration, every year, about 500 thousand surgeons, anesthesiologists, and surgical technologists in the U.S. are exposed to surgical smoke [9]. Surgical smoke can contain toxic gases, pathogens, and aerosols which are harmful to patients and the staff [10].

Electrocution is the most serious side effect of Electrosurgery [7]. In 1993, the American College of Surgeons reported that $54 \%$ of the 506 surgeons at this college had experienced the side effects of work with electrosurgical units [11]. According to the Association of Perioperative Registered Nurses (1999), about 40,000 patients suffer skin burns due to operating room staff's incorrect use of electrosurgical units every year. In addition, the cost of healing these burns is approximately 600 million dollars, which is a significant financial burden on hospitals [12].

The adverse consequences of incorrect application of electrosurgical units originate in users' poor knowledge of the basics of working with these devices. Surprisingly, studies show that surgeons are not sufficiently familiar with the standard principles of using electrosurgical units [11]. and most surgeons, surgical residents, and operating room nurses have not received enough training in the correct use of electrosurgical units[13]. It is vital that all the members of a surgical team be sufficiently familiar with the standard guidelines of using electrosurgical units and knows which tissues of a patient's body are affected during their use of the units [14-15].

To reduce the hazards of the use of electrosurgical units for patients and surgical teams, operating room nurses must be taught the principles of application of electrosurgical units in their training programs [16]. Accordingly, the present study intends to investigate the effects of an educational intervention on operating room nurses' application of electrosurgical units.

\section{Background in Iran}

In Iran, the medical equipment education programs for operating room nurses include a yearly workshop on application of electrosurgical units. The focus of the workshop is on the settings of electrosurgical units and the negative consequences of incorrect use of these units and the safety of patients and the staffs are not properly addressed. Operating room nurses' attendance at the workshop is optional. In addition, during their 4-year education, operating room nurse students receive only 4 hours of training in application of electrosurgical units and this training is exclusively theoretical.

\section{Methods}

Using a quasi-experimental design, the present study was conducted from May 22, 2017 to March 18, 2018 in all the operating rooms of the educational hospitals of Shiraz, the largest city in the south of Iran. The study subjects were the entire operating room nurses who met the inclusion criteria and were willing to participate. The inclusion criteria were having at least an associate degree in nursing and at least 3 months' experience of professional practice in operating rooms. The exclusion criteria were emergency operations and exit from the operating room during surgery. In view of the nature of the behavior under 
study, the researchers used event sampling for data collection. Accordingly, one of the researchers and a trained co-researcher randomly visited the target operating rooms at morning, afternoon, and night shifts and performed direct observations of the operating room Nurses application of electrosurgical units. Each operation was observed as follows: it was divided into 3 time periods (before, during, and after operation) and each period was observed for 40 minutes. Based on the results of a similar study [17] and the following formula, sample size was set at 200 observations.

$$
\mathrm{n}=\frac{\delta_{1-\frac{\alpha}{2}}^{2}}{\mathrm{~d}^{2}}
$$

Thus, the performance of 100 operating room nurses with regard to their application of electrosurgical units in 200 operations (100 before and 100 after the educational intervention) was observed and evaluated. Data were collected using a Demographic Information Questionnaire, a surgery checklist, and the checklist of operating room Nurses application of electrosurgical units. The latter checklist is a researcher-made instrument developed based on a review of literature. The psychometric properties of the checklist were tested using the validity measures of face, content, and construct validity and the reliability measures of internal consistency and inter-rater agreement. The checklist consists of $32 \mathrm{yes} / \mathrm{no}$ questions and the score range is from 0 to 32. The content of the checklist covers four domains: operating room safety and environmental factors, application and maintenance of the units, safety of the patients and personnel, and troubleshooting in the course of application. 8 items address the safety of the personnel and their occupational health, 13 items address the safety of patients, 4 items address the ways of extending the life of the units and preventing damages to them, and 7 items address the safety of the patients and personnel together. The items are to be completed in 3 stages: 18 items evaluate the performance of the Nurses before surgery, 11 items during surgery, and 3 items after surgery. An item is scored 1 if that aspect of the performance of the operating room personnel which it targets is correct; it is scored 0 if it is not. Scores of 0 to 10 indicate poor, 11 to 22 indicate average, and 23 to 32 indicate satisfactory performance of the personnel in relation to their application of electrosurgical units [18].

The educational intervention was implemented through a poster (Fig.1). The content of the poster was the standard principles of using electrosurgical units based on a review of literature, the viewpoints of experts, including operating room faculty members, medical equipment technicians, and the research team, and the guidelines for Electrosurgery as prescribed by the U.S. Association of Operating Room Nurses and the Association of Surgical Technologists. The content of the education addressed the following topics among others: basic knowledge and principles of Electrosurgery, Electrosurgery-related adverse events, interference with other electronic equipment and pacemakers, electrosurgical safety, pediatric consideration, monopolar Electrosurgery, and bipolar Electrosurgery $[16,19]$. 
After 100 operations had been observed in the pretest stage, the posters were put up in prominent positions of the operating rooms and then removed after 1 month. Subsequently, 100 operations similar to the ones observed in the pretest stage were evaluated using the checklist of operating room Nurses application of electrosurgical units. The collected data were analyzed using SPSS v. 18 and Med Calc v. 8. The significance level was set at 0.05 .

\section{Ethical considerations}

All the participants gave written informed consent to participate in the study. The present study was conducted in terms of the principles of the revised Declaration of Helsinki, which is a statement of ethical principles that directs physicians and other participants in medical research involving human subjects. The participants were assured about their anonymity and confidentiality of their information. Moreover, the study was approved by the Institutional Research Ethics Committee of Shiraz University of Medical Sciences Iran (ethical code IR.SUMS.REC.1397. 599)

\section{Results}

The average age of the participating nurses was $31.540 \pm 6.772$ years and the majority of them were female (64\%). $60 \%$ of the participants had never attended a workshop on electrosurgical units. $64 \%$ of the participants had witnessed the adverse consequences of electrosurgical units, e.g. patient burns, during their professional practice (Table 1). Table 2 shows the characteristics of the 200 observed operations, including the fields and types of the operations, the positions of the patients, the placement site of the electrosurgical plates, and the makes of the electrosurgical units. A comparison of the results shows a statistically significant difference between the pretest and posttest mean scores for the nurses' application of electrosurgical units ( $P$-Value $<0.05$ ), which indicates that the educational intervention had affected the operating room nurses' performance (Table 3). Table 4 shows the pretest and posttest frequency distribution values for the different aspects of the operating room nurses' performance as measured by each item on the checklist. For each item, there is a statistically significant difference between the pretest and posttest mean scores for the nurses' application of electrosurgical units ( $P$ Value<0.05) (Table 4).

\section{Discussion}

In the present study, after the introduction of the poster-based educational intervention, the performance of the operating room nurses with regard to their application of electrosurgical units improved in several aspects corresponding to the items of the checklist. Nurses must apply equipment in accordance with standard principles [20], and the results of the present study can help with better standardization of electrosurgical units. Accordingly, it is recommended that educational interventions be used more frequently to enhance compliance with the guidelines for application of electrosurgical units. 
The statistically significant difference between the pretest and posttest performance of the operating room nurses with regard to items $2,3,5,9,11,12,16,21,25,26,27,28$, and 30 shows that they were influenced by the educational content of the poster: the nurses' mean score was significantly higher after intervention. With regard to the other items of the checklist, absence of a statistically significant change in the nurses' performance indicates that the educational intervention had not been effective, which can be attributed to various factors, including lack of specialized equipment in operating rooms or nonstandardization of operating rooms for application of the latest equipment and facilities.

Items 1-8 on the checklist are instructions which are intended to increase the life of electrosurgical units and reduce the risk of electrocution. In order to increase safety and avoid stray voltage, it is vital that all operating rooms be equipped with earthed electrical outlets for electrosurgical units. Earth wires conduct unwanted electricity to the ground so the patient will not be involved in the current and will not suffer electrocution or burns $[16,21]$. In the present study, some of the observed operating rooms which did not have earthed outlets in the pretest stage were found to have been equipped with such outlets after intervention.

Items $11,13,14,15,16,17,18,19,28$, and 32 on the checklist are related to instructions which are intended to minimize the risk of burn injuries for patients. Other similar studies also stress that surgical teams must ensure that patients are not wearing any jewelry or metal belongings, check the security and placement of the return electrode, and examine patients' skin condition before and after surgery $[7,16]$. In the present study, the nurses' performance with regard to ensuring that the patients were not wearing any jewelry or metal belongings and that the return electrodes were securely placed was satisfactory both before and after intervention and there was not a significant difference between their pretest and posttest scores. The nurses' careful implementation of these procedures even before the educational intervention can be attributed to the obvious and immediate impact of incorrect use of electrosurgical units on patients' skin (burns). Another reason may be the imposition of regulations in the operating rooms of Shiraz which dictate that failure to perform the above-mentioned procedures will be recorded in the personnel's files and lead to a pay cut. With regard to examining and recording the skin condition of patients, the nurses' pretest and posttest behaviors were not significantly different, which could have been due to lack of a specialized skin examination checklist.

Item 12 deals with not using monopolar electrodes for patients with pacemakers. The interference of monopolar Electrosurgery with the pace making function of cardiac pacemakers can result in arrhythmia in patients with pacemakers [22]. This interference may change the sinoatrial rhythm to ventricular fibrillation and tachycardia, which can cause death [23].

In the present study, there was not a significant difference between the nurses' pretest and posttest behaviors in this regard, which can be attributed to the fact that their performance was acceptable both before and after intervention. The nurses' satisfactory performance even before the educational intervention can be due to the critical importance of this step, as failure to check whether or not a patient has a pacemaker before he/she undergoes electrosurgery can result in the patient's quick death. 
Item 19 on the checklist addresses the use of specialized tools for cleaning the tips of electrosurgical monopolar pencils. These tips are coated with Teflon and must be cleaned with gauze soaked in saline, as impurities on the tips of the electrodes can prevent effective transfer of electrical currents to tissues [21]. In addition, the tips of the electrodes must not be cleaned with a scalpel as this can result in the spread of tissue particles in the atmosphere of operating rooms [16]. In the present study, the nurses' pretest and posttest behaviors in this regard were not significantly different, which can be due to lack of specialized polishers for the electrosurgical monopolar pencils.

Items 23 and 24 are related to the use of suction systems equipped with smoke absorber filters for the extraction of electrosurgical smoke and the application of high-filtration masks by the members of surgical teams. Electrosurgical smoke not only smells bad, but blocks surgeons' view [24]. Lack of a significant difference between the pretest and posttest results with regard to this aspect of Electrosurgery in the present study is due to lack of specialized suction equipment in the operating rooms under study. Sadly, it appears that the hospitals' authorities did not attach much value to the health and safety of the personnel-even though they invested in expensive advanced equipment to compete with other hospitals, they did allocate a budget for issues with long-term and inconspicuous adverse effects on the health of the personnel.

Item 31 is about removing the tips of electrosurgical pencils: since it is possible that these tips may come off and remain in patients' bodies, they must, according to standard guidelines, be counted at the end of surgery $[16,25]$.

In the present study, the nurses' pretest and posttest behaviors in this regard were not significantly different. This can be explained by the staff's inadequate awareness of the consequences of this occurrence or their dismissal of it due to its rarity.

In view of the serious risks of incorrect application of electrosurgical units to patients on the one hand and the human resources, the most important part of the healthcare system, on the other, effective education and strategies for easing financial pressure on hospitals should be taken more seriously. It appears that continuous education for a constant flow of information about the hazards of electrosurgery and ways of preventing them can prove effective in correcting the belief system of hospital personnel, managers, and surgeons. According to the Association of Perioperative Registered Nurses, educational posters are very economical and have many advantages, including reminding the personnel of the guidelines on a regular basis and saving hospitals money [16]. Overall, in the present study, the performance of the operating room nurses with regard to certain principles of the application of electrosurgical units as described in the checklist improved.

\section{Limitations:}

The limitations of the present study were the time-consuming process of observing the operations. 


\section{Strengths of the study:}

The strengths of the study include: thorough and accurate observations of the operations for evaluation of the operating room nurses' application of electrosurgical units, development of an advanced educational poster, incorporation of up-to-date, standard educational content, employment of an easy-toaccess, low-cost educational approach, and collection of data using a checklist with acceptable psychometric properties. Contribution to the body of professional knowledge: Development of a valid and reliable instrument for the evaluation of operating room personnel's application of electrosurgical units before, during, and after surgery. Development of an advanced educational poster of the guidelines for application of electrosurgical units which incorporates up-to-date, valid educational content for operating rooms. Increasing operating room Nurses knowledge and awareness regarding application of electrosurgical units and decreasing the hazards of incorrect application of these units for patients and surgical teams

\section{Conclusions}

In the present study, after the introduction of the educational intervention, the performance of the operating room nurses in their application of electrosurgical units improved in certain areas. Accordingly, it is recommended that guidelines for application of electrosurgical units be taught through posters because they are cheap, easy to use, remind the staff on a regular basis, and are easy to put up in different spots of operating rooms. As failure to comply with the principles of using electrosurgical units threatens the health of patients and the personnel, nursing managers should take measures to improve the conditions in operating rooms and provide all the necessary equipment. It is also essential that nursing graduates receive the necessary training in application of specialized devices, like electrosurgical units, before they start work in operating rooms.

\section{Declarations}

\section{Ethics approval and consent to participate}

The present research project has been approved by the ethics committee of Shiraz University of Medical Sciences (IR.SUMS.REC.1397.599). Before their participation, the nurses were informed of the objectives of the study and signed the written informed consent form. The participants were assured that all information would remain confidential and anonymous. In compliance with ethical principles, the observations were conducted in an overt manner.

\section{Consent to publish}

Not applicable 


\section{Availability of data and materials}

The datasets used and/or analysed during the current study available from the corresponding author on reasonable request.

\section{Competing interests}

The authors declare that they have no competing interests

\section{Funding}

This research did not receive any specific grant from funding agencies in the public, commercial, or not for profit sectors.

\section{Authors' Contributions}

All authors (CT, AF, MA, MB and SM ) have participated in the conception and design of the study. AF and CT contributed the data collection and pre-pared the first draft of the manuscript. MB, MA and CT, Critically revised and checked closely the proposal, the analysis and interpretation of the data and design the article. All authors read and approved the final manuscript.

\section{Acknowledgements}

This paper was extracted from a research project with the ethical code (IR.SUMS.REC.1397.599) in Shiraz University of Medical Sciences, Shiraz, Iran. The authors appreciate Shiraz University of Medical Sciences for financially supporting this research and triage nurses' who participated in the study.

\section{Authors' Information}

1. Master of perioperative Nursing, School of Nursing and Midwifery, Shiraz University of Medical Sciences, Shiraz, Iran, Shiraz, Iran.2. Ph.D. Candidate of Nursing, Student Research Committee, School of Nursing and Midwifery, Shiraz University of Medical Sciences, Shiraz, Iran.3. Assistant Professor, Department of Medical Surgical Nursing, Fasa University of Medical Sciences, Fasa, Iran .4. Master of Nursing, School of Nursing and Midwifery, Shiraz University of Medical Sciences, Shiraz, Iran. 5. Professor, Community based psychiatric care research center, Department of Community Health Nursing, School of Nursing and Midwifery, Shiraz University of Medical Sciences, Shiraz, Iran 


\section{References}

1. Martinsen T, Pettersen FJ, Kalvøy H, Tronstad C, Kvarstein G, Bakken A, et al. Electrosurgery and temperature increase in tissue with a passive metal implant. Frontiers in surgery. 2019;6.

2. Kumar P, Rattan V, Rai S. Comparative evaluation of healing after gingivectomy with electrocautery and laser. Journal of oral biology and craniofacial research. 2015;5(2):69-74.

3. Coutinho TR, Malafaia O, Torres OJ, Ribas Filho JM, Kaminski AF, Cella IF, et al. Comparison between electrocautery and fibrin selant after hepatectomy in rats. Revista do Colegio Brasileiro de Cirurgioes. 2014;41(3):198-202.

4. Moreira CM, Amaral E. Use of electrocautery for coagulation and wound complications in Caesarean sections. Scientific World Journal. 2014;2014:602375.

5. Shashurin A, Scott D, Zhuang T, Canady J, Beilis, II, Keidar M. Electric discharge during electrosurgery. Scientific reports. 2015;5:9946.

6. Karaca G, Pekcici MR, Altunkaya C, Fidanci V, Kilinc A, Ozer H, et al. The effects of scalpel, harmonic scalpel and monopolar electrocautery on the healing of colonic anastomosis after colonic resection. Annals of surgical treatment and research. 2016;90(6):315-21.

7. Saaiq M, Zaib S, Ahmad S. Electrocautery burns: experience with three cases and review of literature. Annals Of Burns And Fire Disasters. 2012;25(4):203.

8. Alami Harandi M, Bahador, Mehrpour M, Saeed Reza. Electrosurgery (History, Usage principles, Risk Avoidance). Iranian Journal Of Orthpaedic Surgery. 2006;5(1):41-7.

9. King CA. Health care worker safety in surgery. AORN journal. 2011;94(5):457-68.

10. Tan E, Russell K. Surgical plume and its implications: A review of the risk and barriers to a safe work place. The Journal Of Perioperative Nursing In Australia. 2017;30(4):33.

11. Mayooran Z, Pearce S, Tsaltas J, Rombauts L, Brown TI, Lawrence AS, et al. Ignorance of electrosurgery among obstetricians and gynaecologists. BJOG : an international journal of obstetrics and gynaecology. 2004;111(12):1413-8.

12. Meeuwsen FC, Guédon AC, Arkenbout EA, van der Elst M, Dankelman J, van den Dobbelsteen JJ. The art of electrosurgery: Trainees and experts. Surgical Innovation. 2017;24(4):373-8.

13. Bisinotto FMB, Dezena RA, Martins LB, Galvão MC, Sobrinho JM, Calçado MS. Burns related to electrosurgery-Report of two cases. Brazilian Journal Of Anesthesiology (English Edition). 2017;67(5):527-34.

14. Alkatout I, Schollmeyer T, Hawaldar NA, Sharma N, Mettler L. Principles and safety measures of electrosurgery in laparoscopy. Journal Of The Society Of Laparoendoscopic Surgeons. 2012;16(1):130.

15. Ball K, Doyle D, Oocumma NI. Nursing shortages in the OR: solutions for new models of education. AORN journal. 2015;101(1):115-36.

16. Spruce L, Braswell ML. Implementing AORN recommended practices for electrosurgery. AORN journal. 2012;95(3):373-84; quiz 85-7. 
17. Madani A, Watanabe $Y$, Vassiliou MC, Fuchshuber P, Jones DB, Schwaitzberg SD, et al. Long-term knowledge retention following simulation-based training for electrosurgical safety: 1-year follow-up of a randomized controlled trial. Surgical endoscopy. 2016;30(3):1156-63.

18. Torabizadeh C, Fereidouni A, Amiri M, Moayedi SA. Application of Electrosurgical Units by Operating Room Personnel: Development and Psychometric Testing of an Instrument. Shiraz E-Med J. 2020;21(2):e91639.

19. Committee ASTEaPS. Standards of Practice for Use of Electrosurgery 2012

20. Mazhari Z, Adel A. Patient Safety Status In Hospitals Of Tehran-Patient Safety Friendly Hospitals Standards: 2013. Payavard Salamat. 2015;8(5):379-89.

21. Phillips N. Berry \& Kohn's operating room technique. canada: Elsevier Health Sciences; 2016.

22. Pisano P, Jr., Mazzola JG, Tassiopoulos A, Romanos GE. Electrosurgery and ultrasonics on patients with implantable cardiac devices: Evidence of side effects in the dental practice. Quintessence international (Berlin, Germany : 1985). 2016;47(2):151-60.

23. Russo V, Rago A, F DIM, Cioppa ND, Papa AA, Russo MG, et al. Ventricular fibrillation induced by coagulating mode bipolar electrocautery during pacemaker implantation in Myotonic Dystrophy type 1 patient. Acta myologica : myopathies and cardiomyopathies : official journal of the Mediterranean Society of Myology. 2014;33(3):149-51.

24. Gorman T, Dropkin J, Kamen J, Nimbalkar S, Zuckerman N, Lowe T, et al. Controlling health hazards to hospital workers: A reference guide. NEW SOLUTIONS: A Journal of Environmental and Occupational Health Policy. 2014;23(1_suppl):1-169.

25. Nurses AoPR. RP Summary: recommended practices for elec trosurgery. AORN journal. 2012;95(3):388-90.

\section{Tables}


Table 1

Demographics of the participating nurses

\begin{tabular}{|c|c|c|}
\hline Variable & Status & $\begin{array}{l}\text { Absolute frequency (relative } \\
\text { frequency (\%)) }\end{array}$ \\
\hline \multirow[t]{2}{*}{ Gender } & Male & $36(36 \%)$ \\
\hline & Female & $64(64 \%)$ \\
\hline \multirow[t]{2}{*}{ Marital status } & Single & $38(38 \%)$ \\
\hline & Married & $62(62 \%)$ \\
\hline \multirow{3}{*}{ Education } & $\begin{array}{l}\text { Associate } \\
\text { degree }\end{array}$ & $12(12 \%)$ \\
\hline & $\begin{array}{l}\text { Bachelor's } \\
\text { degree }\end{array}$ & $87(87 \%)$ \\
\hline & $\begin{array}{l}\text { Master's } \\
\text { degree }\end{array}$ & $1(1 \%)$ \\
\hline \multirow{3}{*}{ Employment } & Resident & $38(38 \%)$ \\
\hline & Permanent & $49(49 \%)$ \\
\hline & Contractual & $13(13 \%)$ \\
\hline \multirow[t]{2}{*}{ Attendance at workshops } & Yes & $40(40 \%)$ \\
\hline & No & $60(60 \%)$ \\
\hline \multirow{2}{*}{$\begin{array}{l}\text { Experience of adverse events with } \\
\text { electrosurgical units }\end{array}$} & Yes & $54(54 \%)$ \\
\hline & No & $46(46 \%)$ \\
\hline
\end{tabular}


Table 2

Characteristics of the operations before and after intervention

\begin{tabular}{|c|c|c|c|}
\hline Variable & Status & $\begin{array}{l}\text { Before intervention } \\
\text { Absolute frequency } \\
\text { (relative frequency }(\%) \text { ) }\end{array}$ & $\begin{array}{l}\text { After intervention Absolute frequency } \\
\text { (relative frequency }(\%))\end{array}$ \\
\hline \multirow{5}{*}{$\begin{array}{l}\text { Field of } \\
\text { operation }\end{array}$} & Orthopedics & 27 (27\%) & 32 (32\%) \\
\hline & Neurosurgery & $12(12 \%)$ & $18(18 \%)$ \\
\hline & $\begin{array}{l}\text { General } \\
\text { surgery }\end{array}$ & $36(36 \%)$ & $20(20 \%)$ \\
\hline & Urology & $14(14 \%)$ & $14(14 \%)$ \\
\hline & Obstetrics & $11(11 \%)$ & $16(16 \%)$ \\
\hline \multirow[t]{2}{*}{ Gender } & Male & $48(48 \%)$ & $43(43 \%)$ \\
\hline & Female & $52(52 \%)$ & 57 (57\%) \\
\hline \multirow{4}{*}{$\begin{array}{l}\text { Patient } \\
\text { position }\end{array}$} & Supine & 79 (79\%) & 76 (76\%) \\
\hline & Lateral & $7(7 \%)$ & $8(8 \%)$ \\
\hline & Prone & $7(7 \%)$ & $8(8 \%)$ \\
\hline & Lithotomy & 7 (7\%) & $8(8 \%)$ \\
\hline \multirow{3}{*}{$\begin{array}{l}\text { Placement } \\
\text { site }\end{array}$} & Waist & $9(9 \%)$ & $5(5 \%)$ \\
\hline & Lower leg & $69(69 \%)$ & $82(82 \%)$ \\
\hline & Thigh & $22(22 \%)$ & $13(13 \%)$ \\
\hline \multirow{3}{*}{$\begin{array}{l}\text { Make of } \\
\text { unit }\end{array}$} & Matin $^{T M}$ & 75 (75\%) & 75 (75\%) \\
\hline & Avateb $^{\mathrm{TM}}$ & $17(17 \%)$ & $17(17 \%)$ \\
\hline & Valleylab ${ }^{\mathrm{TM}}$ & $8(8 \%)$ & $8(8 \%)$ \\
\hline
\end{tabular}

Table 3

Comparison between the pretest and posttest mean scores for the nurses' application of electrosurgical units

\begin{tabular}{|c|c|c|c|c|c|}
\hline Stage & Mean & Standad deviation & Test statistic & Degrees of freedom (df) & P-Value \\
\hline Pretest & 18.33 & 2.666 & -5.463 & 99 & $<0.001$ \\
\hline Posttest & 20.820 & 3.400 & & & \\
\hline
\end{tabular}

Paired T-test 
Page 14/17 
Table 4

Comparison between the nurses' pretest and posttest application of electrosurgical units as measured by the checklist items individually

\begin{tabular}{|c|c|c|c|}
\hline \multirow[b]{2}{*}{ Item } & Pretest & posttest & \multirow[b]{2}{*}{$\begin{array}{l}\text { P- } \\
\text { Value }\end{array}$} \\
\hline & $\begin{array}{l}\text { Absolute } \\
\text { frequency } \\
\text { (relative } \\
\text { frequency (\%)) }\end{array}$ & $\begin{array}{l}\text { Absolute } \\
\text { frequency } \\
\text { (relative } \\
\text { frequency (\%)) }\end{array}$ & \\
\hline $\begin{array}{l}\text { 1. The cable of the electrosurgical unit is wound } \\
\text { around the unit's generator. }\end{array}$ & $67(67 \%)$ & 74 (74\%) & 0.352 \\
\hline $\begin{array}{l}\text { 2. The electrosurgical unit has been plugged directly } \\
\text { into an earthed power outlet or power distributor. }\end{array}$ & 87 (87\%) & 98 (98\%) & 0.007 \\
\hline $\begin{array}{l}\text { 3. It was ensured that the electrosurgical unit was in } \\
\text { good working order before surgery. }\end{array}$ & $29(29 \%)$ & 30 (30\%) & $<0.001$ \\
\hline $\begin{array}{l}\text { 4. The periodic calibration of the unit has been } \\
\text { performed as instructed by the manufacturer. }\end{array}$ & $96(96 \%)$ & $100(100 \%)$ & 0.129 \\
\hline $\begin{array}{l}\text { 5. The cable of the electrosurgical unit is stretched too } \\
\text { much. }\end{array}$ & $4(4 \%)$ & $10(10 \%)$ & 0.001 \\
\hline $\begin{array}{l}\text { 6. The cable of the electrosurgical unit does not } \\
\text { hamper the movement of the surgical team. }\end{array}$ & $14(14 \%)$ & $40(40 \%)$ & 0.774 \\
\hline $\begin{array}{l}\text { 7. The manual of the electrosurgical unit can be seen } \\
\text { by all the members of the surgical team. }\end{array}$ & 57 (57\%) & 58 (58\%) & 0.477 \\
\hline $\begin{array}{l}\text { 8. The surgical team does not use the generator of the } \\
\text { electrosurgical unit as a table for other surgical tools. }\end{array}$ & $67(67 \%)$ & $61(61 \%)$ & 0.461 \\
\hline $\begin{array}{l}\text { 9. There is a kink in the cable of the electrosurgical } \\
\text { pencil. }\end{array}$ & $22(22 \%)$ & 37 (37\%) & 0.030 \\
\hline $\begin{array}{l}\text { 10. A metal clamp was used to attach the cable of the } \\
\text { electrosurgical pencil to the sterile drape. }\end{array}$ & $9(9 \%)$ & $11(11 \%)$ & 0.813 \\
\hline $\begin{array}{l}\text { 11. Inflammable prep solutions were dried before } \\
\text { draping and application of the electrosurgical unit to } \\
\text { prevent fires and burn injuries to the patient. }\end{array}$ & 44 (44\%) & 95 (95\%) & $<0.001$ \\
\hline $\begin{array}{l}\text { 12. For patients with cardiac pacemakers, active } \\
\text { monopolar electrodes are applied. }\end{array}$ & 98 (98\%) & $100(100 \%)$ & 0.031 \\
\hline $\begin{array}{l}\text { 13. The electrosurgical plate has been attached to a } \\
\text { muscular area of the patient's body, free of moisture, } \\
\text { hair, scars, or tattoos. }\end{array}$ & $81(81 \%)$ & 88 (88\%) & 0.241 \\
\hline $\begin{array}{l}\text { 14. The electrosurgical plate is in full contact with the } \\
\text { patient's body the whole time during surgery. }\end{array}$ & 98 (98\%) & 98 (98\%) & 0.9 \\
\hline $\begin{array}{l}\text { 15. Before being admitted into the operating room, the } \\
\text { patient had to remove all metallic belongings (jewelry, }\end{array}$ & $96(96 \%)$ & $100(100 \%)$ & 0.129 \\
\hline
\end{tabular}


hairclips, etc.).

16. The patient's body is touching the operating table and its metallic accessories.

$92(92 \%)$

$80(80 \%)$

0.016

17. Before application of the electrosurgical unit, the

$22(22 \%)$

$87(87 \%)$

0.090

patient's skin condition was checked and recorded.

18. The size of the electrosurgical plate has been

selected to match the patient's size and age.

$98(98 \%)$

$97(97 \%)$

0.9

19. A special pad or moist gauze is used to clean the tip of the electrosurgical pencil (Scalpels or other

$6(6 \%)$

$10(10 \%)$

0.434

metallic tools are not used).

20. The entire members of the surgical team can hear the sound of the active mode of the electrosurgical

$96(96 \%)$

$99(99 \%)$

0.365

pencil.

21. The tip of the electrosurgical pencil is never placed in a liquid environment.

$40(40 \%)$

$91(91 \%)$

$<0.001$

22. The electrosurgical pencil is placed in a safe and insulated case when it is not in use.

$11(11 \%)$

$17(17 \%)$

0.308

23. The electrosurgical smoke is extracted with a suction system equipped with smoke absorber filters.

24. The members of the surgical team who are exposed to electrosurgical smoke are wearing highfiltration masks (N95).

25 . In the buzzing of forceps, an active current is employed for more than 3 seconds.

$2(2 \%)$

$4(4 \%)$

0.178

26. In the buzzing of forceps, the tip of the active electrode is put in contact with the lower part of the $1(1 \%)$

$3(3 \%)$

0.613 clamp.

27. In the buzzing of forceps, the tip of the active electrode is activated after it is touching the body of $36(36 \%)$

$87(87 \%)$ $<0.001$ the clamp.

28. The settings of the electrosurgical unit have been adjusted to match the conditions (age, tissue, etc.) of $16(16 \%)$

$98(98 \%)$

0.001 the patient.

29. No liquids are poured over any of the parts of the electrosurgical unit.

30. After each surgery, blood or any other fluids splashed over the electrosurgical unit are cleaned as per the instructions of the manufacturer.

31. The tip of the electrosurgical pencil is among the tools that are counted after surgery.

32. After application of the electrosurgical unit, the patient's skin condition is checked and recorded.

$98(98 \%)$

$100(100 \%)$

0.477

$44(44 \%)$

$79(79 \%)$

$<0.001$

$57(57 \%)$

$63(63 \%)$

0.007

$52(52 \%)$

$86(86 \%)$ $<0.001$

$8(8 \%)$

$14(14 \%)$

0.258

$22(22 \%)$

$78(78 \%)$

0.9 


\section{Figures}

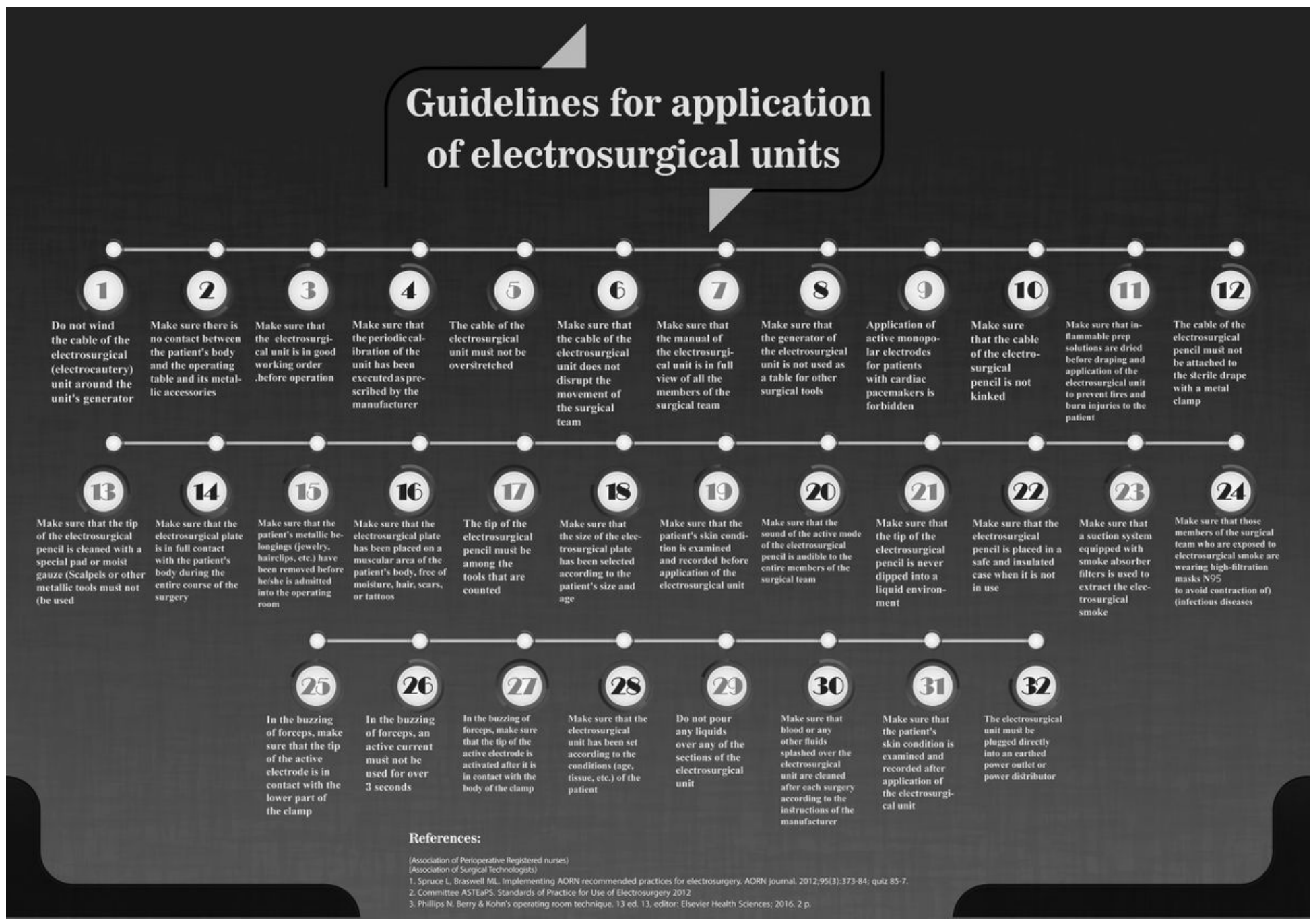

Figure 1

Guidelines for application of electrosurgical units 